\title{
A Study of Clinical and Biochemical Profiles of HIV Subjects in Owerri, Southeast Nigeria \\ (Original Article)
}

\author{
Authors \\ Dr Ernest Ndukaife Anyabolu ${ }^{1,2}$, Dr Innocent Ijezie Chukwuonye ${ }^{1,3}$, \\ Dr Arthur Ebelenna Anyabolu ${ }^{4}$, Dr Okezie Enwere ${ }^{2}$ \\ ${ }^{1}$ Division of Nephrology, Dept of Medicine, Federal Medical Centre, Owerri, Nigeria \\ ${ }^{2}$ Division of Nephrology, Dept of Medicine, Imo State University Teaching Hospital, Orlu, Nigeria \\ ${ }^{3}$ Division of Nephrology, Dept of Medicine, Federal Medical Centre, Umuahia, Nigeria \\ ${ }^{4}$ Division of Respirology, Dept of Medicine, Nnamdi Azikiwe University Teaching Hospital, Nnewi, \\ Nigeria \\ Corresponding Author \\ Dr Ernest Ndukaife Anyabolu
}

Consultant Physician/Nephrologist, Department of Medicine,

Imo State University Teaching Hospital, Orlu, Imo State, Nigeria

Emailenhealer@yahoo.com, Phone 23408035090496

\begin{abstract}
Background and Objectives: The impact of Human immunodeficiency virus (HIV) infection is enormous globally. This study aimed at identifying aspects of clinical and laboratory profile of newly-diagnosed HIV subjects in Owerri, southeast, Nigeria.

Methodology: This was a cross-sectional, descriptive study involving 393 newly-diagnosed HIV subjects and 136 non-HIV, sex- and age-matched Control, consecutively recruited from an HIV clinic and an out-patient clinic of Federal Medical Center, Owerri. Bio-data and anthropometric data were collected. Relevant investigations were performed. Data were compared between HIV subjects and Control.

Results: The mean age of the HIV subjects was $39 \pm 11$ years and Control $39 \pm 12$ years. Female/male ratio was 3:1 in boththe HIV subjects and the Control. Mean waist circumference in male HIV subjects was significantly higher than mean WC in male non-HIV Control $(p=0.013)$. Mean high density lipoprotein cholesterol, $(p<0.001)$, serum creatinine, $(p=001)$, spot urine protein $(S U P),(p=0.013)$, spot urine creatinine, $p<0.001)$, spot urine osmolality, $(p<0.001)$, 24-hour urine protein, $(<0.001)$, 24-hour urine osmolality, $(p<0.001)$, were significantly higher in the HIV subjects than the Control, whereas mean low density lipoprotein cholesterol $(p<0.001)$, hemoglobin, spot urine creatininelosmolality ratio ( $p<0.001)$, 24-hour urine creatininelosmolality ratio, $(p<0.001)$ were significantly lower in HIV subjects than the Control.

Conclusion: Abnormalities of serum creatinine, urine osmolality, urine protein and serum lipids are common among newly-diagnosed HIV subjects in southeast, Nigeria.

There is need to evaluate HIV patients, at inception, for dyslipidemia, anemia and renal damage.

Keywords: Clinical Characteristics, laboratory profile, HIV patients, Owerri, southeast, Nigeria
\end{abstract}




\section{INTRODUCTION}

Worldwide, HIV infection is a great healthcare challenge. Sub-Saharan African countries account for about 24.5 million people living with HIV infection, comprising about $70 \%$ of world total. ${ }^{(1)}$ Nigeria has about 3.5 million of its citizens who are HIV seropositive. ${ }^{(2)}$

HIV infection affects virtually all organs of the body, including the kidneys. These organs may manifest with abnormalities in body biochemistry and hematology. Renal diseases associated with HIV range from acute kidney injury to chronic kidney disease and end-stage-renal-failure. ${ }^{(3-5)}$ Many biochemical abnormalities have also been demonstrated in all stages of HIV-related kidney diseases. ${ }^{(6)}$ Such abnormalities may arise from HIV infection, opportunistic infections, malignancies associated with advanced immunosuppression or drugs used in treating HIV infection and its complications.

Some studies have shown that proteinuria is prevalent in HIV patients. ${ }^{(7-10)}$ Similarly, it has been documented that renal impairment is high in HIV subjects. ${ }^{(11)}$

Hemoglobin levels in HIV subjects decline as HIV infection progresses. ${ }^{(12)}$ Lipid abnormalities have been demonstrated in HIV patients at various stages of the disease. ${ }^{(13)}$ Body mass index and waist circumference have been noted to decrease as HIV infection progresses, in consonance with the name, wasting disease, that HIV infection is sometimes called. ${ }^{(14)}$

Urine osmolality varies over a range of values but may be impaired with involvement of renal tubules in HIV infection. ${ }^{(15)}$

Urine creatinine/osmolality ratio in both spot and random samples were associated with chronic kidney disease in HIV subjects. ${ }^{(11)}$

There is a paucity of studies on laboratory profiles of HIV subjects in Nigeria. We have undertaken this study to evaluate the laboratory profile of HIV subjects in Owerri, southeast Nigeria.

\section{MATERIALS AND METHODS}

This was a cross-sectional, prospective study of clinical and laboratory profile of newlydiagnosed HIV subjects in Owerri, southeast Nigeria. It was a six-month study conducted in 2011 at the Federal Medical Centre (FMC), Owerri, Imo State, Nigeria. FMC Owerri is one of the two tertiary hospitals in the state. It receives referrals from the state and some neighboring states. Imo State has a population of $3,927,563$; about 125,337 of these live in Owerri Municipal. ${ }^{(16)}$

The subjects consisted of 393 newly-diagnosed, 18-65 year-old HIV sero-positive patients and 136 age- and sex-matched, non-HIV Control. The HIV subjects and the non-HIV Control were recruited from the HIV clinic and Medical Out-Patient Department of the hospital respectively. Exclusion criteria for the study population were: age below 18 years and above 65 years, menstruation at the time of sample collection, pregnancy, fever, urinary tract infection, diabetes mellitus, hypertension, heart failure, bladder tumor, chronic use of nephrotoxic drugs, and use of antiretroviral drugs. Subjects who did not freely consent to the study were also excluded.

The Ethical Committee of the FMC Owerri approved the study.

The biographic and anthropometric data were collected by a healthcare provider. Investigations performed on the subjects included HIV screening and confirmatory tests, spot urine protein (SUP), spot urine creatinine (SUCr), spot urine osmolality (SUOsm), serum creatinine ( $\mathrm{SCr}$ ), fasting serum lipid profile, hemoglobin, CD4 cell count, 24-hour urine creatinine (24HUCr),24-hour urine osmolality (24HUOsm), 24-hour urine protein (24HUP). Patients were instructed on how to collect 24-hour urine. Blood samples were collected. 24-hour urine protein/creatinine ratio (24HUPCR), 24-hour urine protein/osmolality ratio (24HUPOR), spot urine creatinine/osmolality ratio (SUCOR), 24-hour urine creatinine/ osmolality ratio (24HUCOR) and creatinine clearance $(\mathrm{ClCr})$ were calculated. 


\section{Statistical Analysis}

Data were analyzed using SPSS version 17.0 (SPSS Inc. Chicago, Il, USA). Chi square was used to compare means. Associations of variables were determined by correlation statistics. $\mathrm{P}<0.05$ was taken as statistically significant.

\section{RESULTS}

A total of 393 HIV subjects and 136 non-HIV Control were studied. The mean age of the HIV subjects was $39 \pm 11$ years and the non-HIV Control $39 \pm 12$ years. There was no significant difference between the mean age of the HIV subjects and the non-HIV Control, $\mathrm{p}=\mathrm{O} .814$. The HIV subjects' age distribution is shown in Figure 1. Out of the 393 HIV subjects, 283 (72.0\%) were females, while $110(28.0 \%)$ were males. The female: male ratio was approximately $3: 1$ in both the HIV subjects and the non-HIV Control. There was no significant difference in the female: male ratio between the HIV subjects and the non-HIV Control, $\mathrm{p}=0.838$.

The HIV subjects comprised of Igbo 92.6\%, Hausa $3.1 \%$, Itsekiri $2.0 \%$, others $2.3 \%$. (Table 1). Tables 2 and 3 show the clinical and laboratory characteristics, respectively, of the study population. The mean BMI in males was significantly higher in the HIV subjects than the Control, $\mathrm{p}<0.001$. However, in females, the mean BMI showed no significant difference between the HIV subjects and the Control, $\mathrm{p}=0.588$. The meanWC for males was low in both the HIV subjects and the Control. However, it was significantly lower in the Control than the HIV subjects, $\mathrm{p}=0.031$.

Conversely, in females, there was no significant difference in the mean WC between the HIV subjects and the Control, $\mathrm{p}=0.253$.

The mean systolic blood pressure in the HIV subjects and the Control did not differ significantly $(\mathrm{p}=0.525)$. There was also no significant difference in the mean diastolic blood pressure between the HIV subjects and the Control, $\mathrm{p}=\mathrm{O} .201$. There was no significant difference in the mean $\mathrm{ClCr}$ between the HIV subjects and the Control, $\mathrm{p}=0.458$. The mean hemoglobin was significantly lower in the HIV subjects compared to the Control, $\mathrm{p}<0.001$. The difference in the mean total cholesterol and triglyceride between the HIV subjects and the Control was not significant, $\mathrm{p}=\mathrm{O} .139$ and $\mathrm{p}=\mathrm{O} .331$ respectively. The mean LDL was significantly lower in the HIV subjects than the Control, $\mathrm{p}<0.001$. However, the mean HDL was lower in the Control than the HIV subjects, $\mathrm{p}<0.001$.

The mean serum creatinine was significantly higher in the HIV subjects compared to the nonHIV Control, $\mathrm{p}<0.001$. The HIV subjects had significantly higher mean SUP than the Control, $\mathrm{p}=0.013$. The mean SUCr did not differ significantly between the HIV subjects and the Control, $p=0.387$. The mean SUOsm was significantly higher in the HIV subjects than the Control, $p=0.001$. The mean 24HUP was significantly higher in the HIV subjects than the Control, $\mathrm{p}<0.001$. The mean SUPCR and SUPOR showed no significant difference between the HIV subjects and the Control, $\mathrm{p}=0.120$ and $\mathrm{p}=\mathrm{O} .357$ respectively. The HIV subjects had significantly higher mean 24HUCr than the Control, $\mathrm{p}<0.001$. The mean 24HUOsm was higher in the HIV subjects than the Control, $\mathrm{p}<0.001$. The HIV subjects had lower mean SUCOR and 24HUCOR values than the Control, $\mathrm{p}<0.001$ for SUCOR and 24HUCOR.

\section{DISCUSSION}

This study determined aspects of clinical and laboratory profiles of newly- diagnosed HIV subjects in Owerri, southeast Nigeria. In the study, the mean age of HIV patients was $39 \pm 11$ years. This is in keeping with the findings of studies done in Nigeria and South Africa. ${ }^{(17,4)}$ This, perhaps, shows a high transmission level among people of this age group, who have been found to have high sexual activity. ${ }^{(18)}$ Females constituted the majority of the patients that presented in the study, with female: male ratio of $3: 1 \quad(p<0.001)$, similar to a report from another study. ${ }^{(16),}$ This is 
in agreement with the fact that female gender is a known risk factor for heterosexual transmission of HIV infection. ${ }^{(18)}$

Majority of the HIV subjects, 92.6\%, were Igbo, apparently reflecting the study domain that was a core Igbo state.

The mean BMI observed in the HIV subjects in our study is similar to that reported inone study. ${ }^{(19)}$ The normal BMI, here, may be because most of the patients recruited in this study were stable asymptomatic individuals who came for voluntary counseling and testing. This may reflect early presentation created by increasing awareness of HIV infection and the availability of free medications. In addition, both BMI and WC were observed in this study to be significantly higher in male HIV subjects than male non-HIV Control. This might suggest that the male HIV subjects probably complied with early HIV screening and detection.

Proteinuria, a marker of renal disease, was high in HIV subjects, compared to non-HIV Control. This observation is close to those reported in studies done in Nigeria with similar occurrence of proteinuria in HIV patients. ${ }^{(7-10)}$ The different methods of assessment of protein in urine did not influence the outcome between the HIV subjects and the non-HIV Control.

In this study, the mean $\mathrm{ClCr}$ in the HIV subjects did not differ significantly from that of the nonHIV Control. Expectedly, drug-naive HIV subjects might not have significant renal involvement.

Both systolic and diastolic blood pressure were found not to differ significantly between the HIV subjects and the non-HIV Control, probably because those who were hypertensive were excluded from the study.

Our study showed that HIV subjects have significantly lower mean hemoglobin than the non-HIV Control. This is in agreement with studies in which anemia was associated with HIV infection. ${ }^{(20,21)}$

Mean total cholesterol and triglyceride were found not to differ significantly between the HIV subjects and the Control. However, the finding of significantly lower LDL and higher HDL in HIV subjects agrees with a report from a study that associated dyslipidemia with HIV infection. ${ }^{(13)}$

In this study, HIV subjects have significantly higher mean serum creatinine than the Control. This tends to suggest that HIV subjects might have higher renal impairment than the non-HIV Control. High renal impairment in HIV infection has been reported in drug-naive early stage as well as in advanced HIV infection. ${ }^{(8,11)}$ No doubt, on a broad note, high serum creatinine is a marker of kidney damage. However, serum creatinine-based equations are preferred for the assessment of renal function. ${ }^{(22)}$ The higher the serum creatinine, the lower the glomerular filtration rate, and, by extension, the worse the degree of renal impairment. $^{(22)}$

We found that mean SUP was significantly higher in HIV subjects than the Control. Although SUP has variable values during the day and may not reflect real time 24- hour urine protein excretion, ${ }^{(23)}$ still very high values may be a pointer to renal damage.

This study showed that there was no significant difference in the mean SUCr between the HIV subjects and the Control. SUCr is known to vary over 24 hours of the day and may not indicate quantitatively the presence of renal damage. ${ }^{(1)}$

The mean SUOsm was, as found in this study, to be significantly higher in HIV subjects than the Control. High SUOsm may suggest a high capacity to regulate and concentrate urine by the kidney. In contrast, reduced ability to concentrate urine has been found as HIV infection progressed, indicating the presence of renal damage. ${ }^{(15)}$

The mean 24HUP was significantly higher in HIV subjects than the Control. However, both mean SUPCR and mean SUPOR were found not to differ significantly between the HIV subjects and the Control. By inference, HIV subjects excreted more 24-hour urine protein than the Control.

We also found that the mean $24 \mathrm{HUCr}$ was significantly higher in the HIV subjects than the 
Control. However, low $24 \mathrm{HUCr}$ may indicate renal impairment. ${ }^{(24)}$

The mean 24HUOsm was significantly higher in HIV subjects than the Control. This contrasts with a study in which low values of 24HUOsm were associated with advanced HIV infection. ${ }^{(15)}$

Both the mean SUCOR and 24HUCOR were significantly lower in HIV subjects than the
Control. One study has reported that both SUCOR and 24HUCOR were associated with chronic kidney disease in HIV subjects but not in nonHIV Control. ${ }^{(11)}$ Therefore, low values of these indices suggest the presence of renal damage in the HIV subjects in our study.

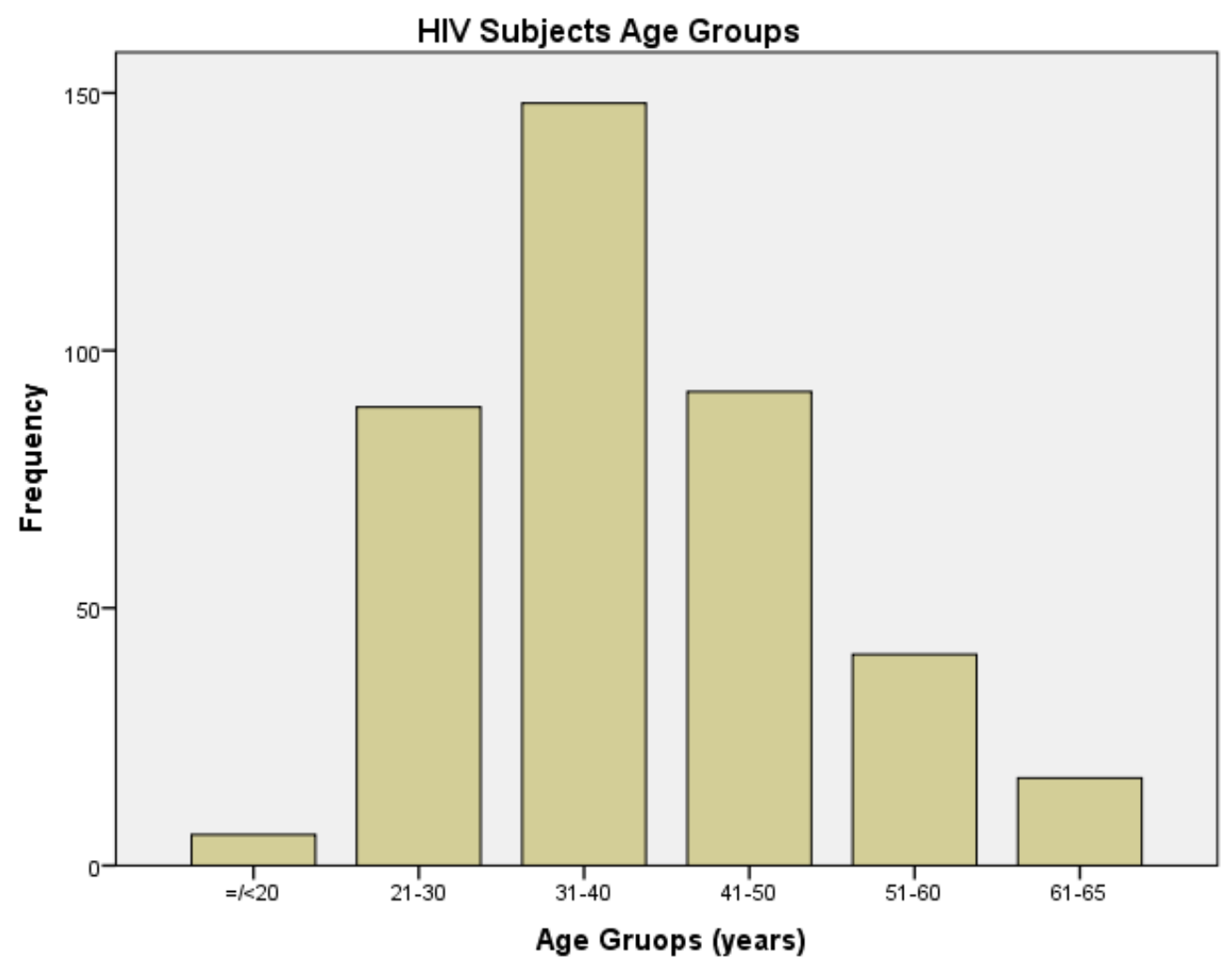

FIGURE 1: HIV Subjects Age Group Distribution 
Table 1: Clinical characteristics of the study population

\begin{tabular}{|c|c|c|c|c|}
\hline Variable (mean) & $\begin{array}{l}\text { All subjects } \\
(n=529)\end{array}$ & $\begin{array}{l}\text { HIV subjects } \\
\quad(n=393)\end{array}$ & $\begin{array}{c}\text { Control } \\
(n=136)\end{array}$ & p value \\
\hline $\operatorname{Age}(\mathrm{yrs} \pm \mathrm{SD})$ & $39 \pm 11$ & $39 \pm 11$ & $39 \pm 12$ & 0.814 \\
\hline \multicolumn{5}{|l|}{ Gender: } \\
\hline Male (\%) & $148(28 \%)$ & $110(28 \%)$ & $38(27.9)$ & \\
\hline Female(\%) & $381(72 \%)$ & $283(72.0 \%)$ & $98(72.1 \%)$ & \\
\hline \multicolumn{5}{|l|}{ Tribe } \\
\hline Igbo & & 364(92.6) & 121(89.0) & \\
\hline Hausa & & $12(3.1)$ & $4(2.9)$ & \\
\hline Itsekiri & & $8(2.0)$ & $2(11.5)$ & \\
\hline Others & & $9(2.3)$ & $7(5.2)$ & \\
\hline $\mathrm{BMI}\left(\mathrm{kg} / \mathrm{m}^{2} \pm \mathrm{SD}\right)$ & $26.04 \pm 5.69$ & $26.22 \pm 5.40$ & $25.51 \pm 6.47$ & 0.211 \\
\hline Male & $2434 \pm 4.92$ & $25.24 \pm 4.69$ & $21.74 \pm 4.66$ & $<0.001$ \\
\hline Female & $26.70 \pm 5.84$ & $26.61 \pm 5.61$ & $26.98 \pm 6.50$ & 0.588 \\
\hline Waist ${ }^{+} \mathrm{C}(\mathrm{cm} \pm \mathrm{SD})$ & $84.66 \pm 12.91$ & $85.34 \pm 13.35$ & $82.69 \pm 11.36$ & 0.039 \\
\hline Male & $83.55 \pm 12.15$ & $84.82 \pm 12.54$ & $79.89 \pm 10.27$ & 0.031 \\
\hline Female & $85.09 \pm 13.19$ & $85.54 \pm 13.67$ & $83.78 \pm 11.62$ & 0.253 \\
\hline $\mathrm{BP}(\mathrm{mmHg} \pm \mathrm{SD})$ & $119.6 \pm 16.9$ & $119.3 \pm 16.5$ & $120.4 \pm 18.2$ & 0.525 \\
\hline $\mathrm{DBP}(\mathrm{mmHg} \pm \mathrm{SD})$ & $75.9 \pm 10.6$ & $75.6 \pm 10.6$ & $76.9 \pm 10.7$ & 0.201 \\
\hline
\end{tabular}

$\mathrm{BMI}=$ Body mass index, $\mathrm{WC}=$ Waist circumference, $\mathrm{SBP}=$ Systolic blood pressure, $\mathrm{DBP}=\mathrm{Diastolic}$ blood pressure, $\mathrm{SD}=$ standard deviation.

Table 2: Laboratory characteristics of the study population

\begin{tabular}{|c|c|c|c|c|}
\hline \multirow[t]{2}{*}{ Variable (mean) } & \multirow{2}{*}{$\begin{array}{l}\text { All subjects } \\
\qquad(n=529)\end{array}$} & HIV subjects & Control & \multirow[t]{2}{*}{$\mathrm{p}$ value } \\
\hline & & $(n=393)$ & $(n=136)$ & \\
\hline $\mathrm{ClCr}(\mathrm{mls} / \mathrm{min} \pm \mathrm{SD})$ & $91.84 \pm 21.32$ & $91.42 \pm 22.98$ & $93.01 \pm 15.91$ & 0.458 \\
\hline $\mathrm{Hb}(\mathrm{g} / \mathrm{dl} \pm \mathrm{SD})$ & $11.6 \pm 1.93$ & $11.2 \pm 1.8$ & $12.9 \pm 1.6$ & $<0.001$ \\
\hline FSLP(mmol/lıSD) & & & & \\
\hline Total cholesterol & $4.30 \pm 1.00$ & $4.26 \pm 0.90$ & $4.41 \pm 1.25$ & 0.139 \\
\hline LDL cholesterol & $2.26 \pm 0.82$ & $2.05 \pm 0.58$ & $2.87 \pm 1.07$ & $<0.001$ \\
\hline HDL cholesterol & $1.13 \pm 039$ & $1.18 \pm 0.39$ & $0.97 \pm 0.34$ & $<0.001$ \\
\hline Triglyceride & $1.24 \pm 0.37$ & $1.23 \pm 0.37$ & $1.27 \pm 0.40$ & 0.331 \\
\hline $\operatorname{SCr}(\mathrm{mg} / \mathrm{dl} \pm \mathrm{SD})$ & $0.99 \pm 0.38$ & $1.03 \pm 0.42$ & $0.88 \pm 0.19$ & $<0.001$ \\
\hline $\mathrm{SUP}(\mathrm{mg} / \mathrm{dl} \pm \mathrm{SD})$ & $10.69 \pm 19.04$ & $11.89 \pm 19.13$ & $7.19 \pm 18.39$ & 0.013 \\
\hline SUCr(mg/dl $\pm S D)$ & $139.87 \pm 119.98$ & $8137.21 \pm 98.47$ & $147.55 \pm 176.43$ & $\begin{array}{ll}3 & 0.387\end{array}$ \\
\hline SUOsm & & & & \\
\hline$\left(\mathrm{mOsm} / \mathrm{kgH}_{2} \mathrm{O} \pm \mathrm{SD}\right)$ & $430 \pm 261$ & $464 \pm 271$ & $334 \pm 204$ & $<0.001$ \\
\hline 24HUP(g士SD0. & $162 \pm 0.256$ & $0.187 \pm 0.290$ & $0.095 \pm 0.087$ & $<0.001$ \\
\hline $\operatorname{SUPCR}(\mathrm{mg} / \mathrm{mg} \pm \mathrm{SD})$ & $0.120 \pm 0.330$ & $0.133 \pm 0.371$ & $0.082 \pm 0.163$ & 0.120 \\
\hline $\begin{array}{l}\text { SUPOR } \\
\text { (mg/dl/mOsmol// }\end{array}$ & & & & \\
\hline $\left.\mathrm{kgH}_{2} \mathrm{O} \pm \mathrm{SD}\right)$ & $0.037 \pm 0.081$ & $0.035 \pm 0.050$ & $0.042 \pm 0.0 .357$ & \\
\hline 24HUCr(mg士SD & $\begin{array}{l}1425.63 \\
+701.56\end{array}$ & $\begin{array}{l}1506.88 \\
+78138\end{array}$ & 1202.96 & $<0.001$ \\
\hline
\end{tabular}


24HUOsm

$(\mathrm{mOsm} \pm \mathrm{SD})$

SUCOR

$\left(\mathrm{mg} / \mathrm{dl} / \mathrm{mosm} / \mathrm{H}_{2} \mathrm{O}\right)$

24HUCOR

$(\mathrm{mg} / \mathrm{mOsm} \pm \mathrm{SD})$
$489 \pm 465 \quad 564 \pm 501$

$0.475 \pm 0.5830 .422 \pm 0.486$

$0.528 \pm 0.450 \quad 0.460 \pm 0.426$
$284 \pm 253<0.001$

$0.628 \pm 0.728<0.001$

$0.707 \pm 0.468<0.001$

$\mathrm{ClCr}=$ Ceatinine clearance, $\mathrm{Hb}=$ Hemoglobin, FSLP=Fasting serum lipid profile, LDL=Low density lipoprotein cholesterol, HDL=High density lipoprotein cholesterol, $\mathrm{SCr}=\mathrm{Serum}$ creatinine, SUP=Spot urine protein, $\mathrm{SUCr}=\mathrm{Spot}$ urine creatinine, $\mathrm{SUOsm}=\mathrm{Spot}$ urine osmolality, 24HUP=24-hour urine protein, SUPCR=Spot urine protein/creatinine ratio, SUPOR=Spot urine protein/osmolality ratio, $24 \mathrm{HUCr}=24$-hour urine creatinine, 24HUOsm=24-hour urine osmolality, SUCOR=Spot urine creatinine/osmolality ratio, 24HUCOR=24-hour urine creatinine/osmolality ratio,

\section{CONCLUSION}

Female gender and young age are associated with HIV infection. Abnormalities of serum lipid, serum creatinine, urine protein, urine creatinine and urine osmolality are common in newlydiagnosed HIV subjects in southeast Nigeria. There in need to evaluate HIV patients, at inception, for dyslipidemia, anemia and renal damage.

Support: There is no support from any person or group of persons.

Conflicts of interest: There is none.

Permissions: There is none.

\section{REFERENCES}

1. UNAIDS. Gap Report 2014. Page 26

2. Anabel Ki, Jenni F: Graham Pembrey, (ed) HIV and AIDS in Africa. UNAIDS Report 2008.

3. Nochy D, Glotz D, Dosquet P, Pruna A, Guettier C, Weiss L, et al. Renal disease associated with HIV infection: a multicentric study of 60 patients from Paris hospitals. Nephrol Dial transpl. 1993; 8(1): 11-19.

4. Okpechi IG, Swanepoel CR. Patterns of renal disease in Cape Town South Africa: a 10 year review of a single center renal biopsy database. J NephrolHypertens. 2011; 25(1): 11-15.
5. Rao TK, Friedman EA, Nicastri AD. The types of renal disease in the acquired immunodeficiency syndrome. $\mathrm{N}$ Eng $\mathrm{J}$ Med. 1987; 316(17): 1062-1068.

6. Okecuhukwu Ibeh BO, Omodamiro OD, Ibeh U, Habu JB Biochemical and haematological changes in HIV subjects receiving winnie cure antiretroviral drug in Nigeria. J Biomed Scie 2013, 20: 73 doi:10.1186/1423-0127-20-73

7. Emem CP1, Arogundade F, Sanusi A, Adelusola K, Wokoma F, Akinsola A. Renal disease in HIV-seropositive patients in Nigeria: an assessment of prevalence, clinical features and risk factors. Nephrol Dial Transpl 2008; 23: 741-746.

8. Agaba EI,Agaba PA,Sirisena ND,Anteyi EA,Idoko JA. Renal disease in the acquired immunodeficiency syndrome in north central Nigeria.Niger J Med. 2003; 12:120-5.

9. Okafor UH, Unuigbe EI, Ojogwu LI, Oviasu E, Wokoma FS. Renal disease in HIV-infected patients at University of Benin Teaching Hospital in Nigeria. Afr Health Sci 2013; 51: 528-533

10. Umeizudike T, Mabayoje M, Okany C, Abdulkareem F, Adeyomoye A, Okubadejo N, Okpechi I. Prevalence of chronic kidney disease in HIV positive patients in Lagos, south-west Nigeria. Nephrology Rev 2012; 4; 22-26. 
11. Anyabolu EN, Chukwuonye II, Arodiwe E, Jjoma CK, Ulasi I. Prevalence and Predictors of Chronic Kidney Disease in Newly-diagnosed Human Immunodeficiency Virus Patients in Owerri, Nigeria. Indian J Nephrol (ahead of print cited 2015 July 28) Available htt://www.indianjnephrol.org/preprintarticl e.asp? id=156115

12. Obirikorana C, Yeboah FA. Blood haemoglobin measurement as a predictive indicator for the progression of HIV/AIDS in resource-limited setting. J Biomed Sci. 2009; 16(1): 102.

13. Adewole OO, Eze S, Betiku Ye, Anteyi E, Wada I, Ajuwon Z, et al. Lipid profile in HIV/AIDS patients in Nigeria.Afr Health Sci. 2010 Jun; 10(2): 144-149.

14. Takara LS, Steven KG. Body Composition and Metabolic Changes in HIV-Infected Patients. J Infect Disease. 2015; 205(3): 5383-5390.

15. Waldo HB, Mariana de Paz S, Matilde N, Marisa L, Aeiel G. Impaired Urine Dilution Capability in HIV Stable Patients. Int J Nephrol. 2014; 2014: 381985.

16. Federal Republic of NigeriaGlobal AIDS Response and Progress Report 2012.

17. Akimbani A, Dosumnmu IA, Adeniran IA, Ajibola S,Oshinaike O, et al. CD4 count pattern and demographic distribution of treatment-naïve hiv patients in Lagos, Nigeria. AIDS Res Treatment. 2012; 2012 (2012): 6 pages.

http://dx.doi.org/10.1155/2012/352753

18. Ramjee G, Daniels B. Women and HIV in Sub-Saharan Africa. AIDS Res Therapy. 2013; 10:30 doi:10.1186/1742-6405-10-30

19. Mariz C, Mlitao de Albuquerque, Ximenses RA, Lacerda de Melo R, Bandeira $F$, et al. Body mass index in individuals with HIV infection and factors associated with thinness and overweight/obesity. Cad. Saude Publica 2011; 27: 10.

20. Mohsen M, Fashid R, Mohammad RM,Majid A, Katayoun T. Prevalence, severity, and related factors of anemia in HIV/AIDS patients. J Res Med Sci. 2012 Feb; 17(2): 138-142.

21. Hylemariam M, Bineyam $T$, Aster $T$. Magnitude of Anemia and Associated Factors among Pediatric HIV/AIDS Patients Attending Zewditu Memorial Hospital ART Clinic, Addis Ababa, Ethiopia. Anemia 2015; Vol 2015(2015) http://dx.doi.org/10.1155/2015/479329

22. ShemeshO,Golbetz H, Kriss JP, Myers BD. Limitations of creatinine as a filtration marker in glomerulopathy patients. Kid Int 1985; 28: 830-838.

23. Savita RS, Veena G, Shashu L, Himanshu M, Veenu K, Ashuma S. Correlation of 2 Hour, 4 Hour and 12 Hour Urine Protein with 24 Hour Urinary Protein in Preeclampsia.

24. J Family Reprod Heath. 2014 Set, 8(3): 131-134.

25. Kalantari K, Bolten K. A good Reason to Measure 24-Hour Urine Creatinine Excretion, but Not to Assess Kidney Function. Clin J Am SocNephrol. 2013 Nov 7; 8(11): 1847-1849. 